was supposed to be in a tit. She had gone to bed at 11 P.M. She had been in the habit of indulging in chloral and also in cocaine at home, but she had taken very little while at Davos. A physician in London had given her cachets of chloralose, eight grains in each, to take for sleeplessness. She took one for the first time that night. I found her in great distress, unable to move her legs or her arms, with a feeling of numbness in them, the numbness being more marked on the right side. She could not move. Her mind was clear but her speech was slow. Her pulse was good. She recovered in five or six hours. A week afterwards she took another cachet and $I$ was called at about 1 A.M. by her friend who slept in her room because she would not answer when spoken to and again was thought to be in a fit. She was in a cramped-up posture of emprosthotonos, her thighs were tightly flexed on her abdomen, and her chin was forced down on ber chest. Respiration was almost inappreciable and very slow and she was cyanosed. Her pulse was 80 and fairly good. Her extremities were not cold. She was quite unconscious and I could not rouse her. I had difficulty in overcoming the contraction of her limbs and neck, but having done so I performed artificial respiration for half an hour, whilst others applied very hot water to her chest and head, and as soon as she could swallow we forced down some brandy, and her breathing improved, but was very slow. In an hour it was possible to get a grunt in reply to questions. She remained in that state for six hours and was torpid all the next day, then seemed quite herself again. The small extent to which the heart seemed affected on each occasion quite bore out Professor Bradbury's observations in his experiments.

Davos Platz.

\section{A eftlitror}

or

\section{HOS PITAL PRACTICE,}

\section{BRITISH AND FOREIGN.}

Fulla autem est alia pro certo noscendi via, nisl quamplurimas et morborum et dissectionum historias, tum aliorum tum proprias collectas habere, et inter so comparare.-MoresanI De Sed. et Caus. Morb., lib. iv. Procminm.

\section{MIDDLESEX HOSPITAL.}

A CASE OF PERFORATED GASTRIC ULCER.

(Under the care of Mr. T. H. KELLOCK.)

IN the lectures on the Surgery of the Stomach delivered in March last by Professor Mayo Robson there are given statistics of 429 cases of perforated gastric ulcer treated by operation. Of these 193 patients recovered and 236 died. ${ }^{1}$ This is a mortality of 55 per cent. The most important element in prognosis in cases of perforation treated by laparotomy is the length of time which has elapsed before the operation is performed. In the lectures already quoted it is shown that of cases under 12 hours the death-rate was 28 per cent. ; from 12 to 24 hours it was 63 per cent. ; and from 24 to 36 hours it was 87 per cent. For the notes of the case we are indebted to $\mathrm{Mr}$. R. Ainsworth, house surgeon, and Mr. C. W. Rowntree, dresser.

A single woman, 22 years of age, a domestic servant, was admitted into the Middlesex Hospital at 1 A.M. on Sept. 20th, 1900, suffering from vomiting and pain in the back, shoulders, and abdomen. She stated that for five years she had suffered severe pain after taking food; the pain came on immediately after a meal and was most acute in the epigastrium. She had occasionally vomited about a quarter of an hour after a meal and the pain was then much relieved; on one or two occasions there had been a little blood in the vomited material. She had also suffered from amenorrhoea and dysmenorrhcea and had been under treatment on and off for the whole period of five years. At 9 P.M. on the previous evening she had a supper of hashed meat and half an hour later was seized with sudden severe pain in the epigastric region which was worse than she had ever experienced. She was given some brandy which she at once vomited, and shortly afterwards she vomited again, but there was no blood in the vomited matter

1 THE LANCET, March 17th, 1900, p. 748. on either occasion. As the pain became worse and as she was obviously very ill Dr. Percy Edmunds was summoned. He saw ber three-quarters of an hour after the onset of acute symptoms and found her suffering then from pain almost entirely confined to the neighbourhood of the scapulæ and clavicles, and he also noted that her face was markedly of the "abdominal" type $\mathrm{He}$ diagnosed a perforated gastric ulcer, administered two grains of opium, and advised her immediate removal to the hospital.

On admission the patient appeared to be seriously ill Her face was very pale and drawn and she complained of pain in the back between the shoulders and in the epigastric region, but it did not seem to be very severe; there was no retching or hiccough. The pupils were not contracted. The pulse was 120 per minute, of very poor volume, and occasionally dicrotic, the respirations were increased in frequency, short and grunting in character, and the temperature was $100^{\circ} \mathrm{F}$. The abdomen was somewhat distended and moved very little with respiration ; there was consider. able muscular rigidity on palpation, especially in the epigastrium and below the right costal margin, but very little tenderness. There was no dulness in the flanks and no fluid thrill was to be obtained; a tympanitic stomach note could be obtained on percussion over the left lower ribs nearly to the level of the umbilicus; the liver dulness was present down to the right costal margin.

Mr. Kellock saw the patient at 2 A.M. and decided on immediate operation. The abdomen was opened by an incision in the middle line reaching from the xiphisternum to the umbilicus. On opening the peritoneum a fair quantity of thin turbid whitish fluid escaped. On drawing up the left lobe of the liver the stomach was seen to be somewhat distended, its anterior surface was covered with lymph, and the vessels were intensely congested. The lesser curvature was fixed by adhesions so that it could not be drawn up. On examination of the upper border a perforation of about the size of a sixpence was found near the cardiac end, through which gas and fluid came when the stomach was manipulated. The edges of the perforation and the wall of the stomach in its neighbourbood were very hard and indurated. Owing to the density of the adhesions the closing of the opening had to be done without bringing it up to the surface; the edges were first brought together by fine silk interrupted sutures and a row of Lembert's sutures was then inserted, turning in the peritoneal and muscular coats of the stomach all round the perforation. The peritoneal cavity was cleansed by means of sponges, very little extravasation of the contents of the stomach being found except at the upper part in the immediate neighbourhood of the stomach and liver. A rubber drainage-tube was inserted leading down almost to the site of the perforation, the peritoneum was closed round it by a continuous silk suture, the skin and muscles were united by silkworm gut and horsehair sutures, and a dressing of cyanide gauze and sal.alembroth wool was applied.

The patient bore the operation very well; on its completion she was given a quarter of a grain of morphia hypodermically, after which she was very quiet for some hours and free from pain; she vomited slightly once, bringing up some greenish fluid. Eight hours after the operation the pulse had fallen to 96 per minute, the facial expression was improved, and the abdomen moved with respiration slightly more freely and was free from tenderness. A little blood stained discharge came from the drainage-tube at first; on the second day a drain of iodoform gauze was substituted for the tube, and this was again changed on the third day for a strip of oiled silk which was continued for three days and then omitted as the discharge bad practically ceased. For four days the patient was fed entirely by the rectum, plain water being given at first and subsequently peptonised milk and beef-tea. This was discontinued gradually and feeding by the mouth with milk-and-water was commenced. She suffered very little pain in the abdomen after the second day when it was relieved by a hypodermic in jection of morphia By Oct. 2nd she was having all her nourishment by the mouth; she was then given palatinoids of carbonate of iron and a little liquid extract of cascara sagrada. The stitches were removed on the twelfth day, the wound being soundly healed except where the drainage-tube had been. The temperature rose to $101^{\circ}$ on the first day but subsequently was practically normal. The patient was sent to a convalescent home on Oct. 18th, the wound being then quite healed, her anæmia had much improved and she was taking a fair amount of solid food without pain or discomfort.

Remarks by Mr. KELLock.- Owing to the early diagnosis 
that had been made in this case we were fortunately able to operate within five hours of the onset of the acute symptoms; the opium which had been given previously to the patient's admission to the hospital had, by relieving the pain, masked one of the important symptoms, but it probably helped very considerably in the successful issue by lessening the movements of the stomach and intestines and so prevented any great extravasation of the contents of the stomach. The history of the case, the rapid feeble pulse, and the rigid, almost motionless abdominal wall, combined with the marked abdominal facial expression, seemed to be sufficient evidence of what had occurred. The strong adhesions about the lesser curvature of the stomach rendered the suturing of the perforation difficult, as it had to be performed at some depth owing to the impossibility of bringing the organ to the surface without separating them ; the density of these adheslons showed them to be of some standing, and it is quite possible that it was they that had given way at the time of the acute onset of symptoms and allowed the contents of the stomach to escape through a previously existing perforation in its wall. The limited area of peritoneum soiled by the contents of the stomach rendered the cleansing of the cavity easy and capable of being carried out with very little disturbance of the intestines and other viscera.

\section{WOLVERHAMPTON AND STAFFORDSHIRE} GENERAL HOSPITAL.

A CASE OF CHONDRO-CARCINOMA OF THE RIGHT TESTIS, FOR WHICH CASTRATION WAS PERFORMED.

(Under the care of Mr. T. VINCENT JACKSON.)

MANY tamours of the testis are found to contain portions of cartilage embedded in their substance, and the only other organ which is similarly affected with equal frequency is the parotid gland. Another pathological bond of connexion between these two organs is the fact that the inflammatory process in mumps is liable to involve both of them. Malignant growths may arise in healthy tissues or they may involve, as in the case recorded below, non-malignant tumours; and in such cases the malignant growth has probably attacked the pre-existing tumour because of its low power of resistance.

A man, aged 40 years, was sent to $\mathrm{Mr}$. Vincent Jackson by Dr. Sydney Partridge and was admitted into the Wolverhampton and Staffordshure General Hospital on Sept. 9th, 1900, on account of a sarcocele of the right testicle. The patient was married and his circumstances were ample for his position in life. He had not been troubled with any particular care or mental anxiety, his health and appetite were good, and he had maintained his ordinary habit of bodp. There was a clean sheet as regards any hereditary tendency to malignant disease, and none of the present generation of his relatives had been victimised by this disease in any of its forms. The previous history was very incomplete, but the patient was decided on the fact that he had never suffered from syphilis or traumatism. His personal knowledge of the enlargement of the testicle dated back only seven or eight months ; probably this is to be accounted for by the absence, or almost the entire absence, of any subjective symptoms. The growth, however, continued, and as the weight appeared to cause lumbar pain he sought advice.

On examination the testicle, supported by the left hand, appeared to the eye to be massive in size and in weight unusually heavy, and all over it was non-resistant, with no suspicion of fluid. There were no isolated masses of cartilage ; the tumour was non-transparent; bere and there subcutaneously a distended vein was visible. No glandular enlargement was detected either by superficial or deep pressure in the right inguinal region. The condition of the lumbar lymphatic glands was undetermined. The liver was not enlarged. No diagnosis was made as between sarcoma and carcinoma. The report as to the urine was favourable.

On Sept. 12th, under an anæsthetic, the right testicle was removed, care being taken to detach with it as much of the cord as could be reached. The organ weighed over a pound and a portion was sent to the Clinical Research Association for examination and a report. On the 21 st the scrotal wound had quite healed, and on the 26 th the patient left his bed. On the 28th an unexpected incident occurred, for in the morning hæmoptysis supervened and every effort was made to determine the cause. All physical means, sucb as percussion and the use of the stethoscope and of the thermometer, were resorted to, but with a negative result, no evidence of tuberculous deposit being detected. Several specimens of sputum were examined and no tubercle bacilli were found. There was no disease or enlargement of the aorta. On Oct. 5th there was obtained from the Jenner Institute of Preventive Medicine a 10 per cent. dilution of Koch's original tuberculin. An injection of 0.01 cubic centimetre dilnted with 1 in 100 carbolic acid was given. On the 8th 005 cubic centimetre diluted as before with carbolic acid was injected. In each case, five hours after the injection, a rise of temperature to $99.2^{\circ} \mathrm{F}$. took place, the general symptoms being nil. Dr. E. C. Morland. house physician, undertook the above test assisted by Mr. S. Southall, house surgeon. The presence of tubercle having been negatived by every diagnostic test used, it was felt that the cause of the hæmorrhage might be a cancerous deposit of the lungs. On the 12 th the patient wished to be discharged. The expectoration now consisted of a little mucus, containing occasionally a little blood. On Nov. 14th Mr. Jackson received an announcement from the patient's wife that her husband bad died on Nov. 3rd from a severe and uncontrollable attack of lung-bleeding. Later, Mr. Jackson was instructed that the patient had been buried without any post-mortem examination of the lungs.

Microscopical examination.-Mr. J. H. Targett's report on the specimen sent to the Clinical Research Association is as follows: "This is a composite tumour of the testis, congenital in origin. There are nodules of cartilage, bands of unstriped muscle, and tubulæ lined with columnar-ciliated epithelium. Some of the cysts are filled with laminated epithelium which is undergoing a keratoid change. But the strangest thing in the section is an apparent infection with recent tubercle. Groups of giant cells are seen resembling those of tubercle, though they may be of the nature of phagocytes, although it is certain that tumours of all kinds may become infected with tubercle. The tumour is malignant in its present condition, though starting probably in some congenital inclusion. The term 'chondro-carcinoma' is now sometimes applied to this variety of growth. In the absence of other evidence I should not like to speak definitely about the tuberculous infection. It is a very interesting specimen."

Remarks by Mr. JACKSON.-On carefully considering the report of the microscopical examination of the tumour it seems to be very difficult to classify it accurately, for it contains a mixture of dissimilar elements which renders it scientifically distinct from an ordinary example of cancer.

\section{attedical Socrefties.}

\section{PATHOLOGICAL SOCIETY OF LONDON.}

Chronic Mastitis and its Relation to Tumour Formation.Broncho-cesophageal Fistula.-Bamorrhagic Pancreatitis with Fat Necrosis.

A MEETING of this society was held on Dec. 18th, Mr. W. WATSON CHEYNe, the President, being in the chair.

Mr. F. T. PAUL (Liverpool) read a paper on Chronic Mastitis and its Relation to Tumour Formation (illustrated by a lantern demonstration and microscopic specimens). He commenced by remarking that the tenciency of chronic inflammation of the mammary gland to end in tumour formation was a fact by which he was more impressed every year. It was well known that cancerous breasts almost constantly showed microscopical changes indicating a preceding chronic mastitis, and that breasts removed for simple chronic mastitis frequently presented appearances suggestive of the commencement of cancer. The same was also true of innocent tumours, even of those occurring early in life. The varieties of chronic mastitis were discussed. In the tuberculous form of mastitis actinomycotic-like bodies were described as present in five or six cases. In the simple form of mastitis it was considered that there was no true pathological distinction between cases occurring in early life 